\title{
Laboreal
}

Volume $14 \mathrm{~N}^{\circ} 1$ | 2018

O regresso ao emprego após um acidente de trabalho

\section{El modo de existencia de los objetos técnicos: introducción}

Texto original: Simondon, G. (1969). Introduction. In G. Simondon. Du mode d'existence des objets techniques (pp. 9-16). Paris: Aubier.

Do modo de existência dos objetos técnicos: introdução

Du mode d'existence des objets techniques: introduction

On the mode of existence of technical objects: introduction

\section{Gilbert Simondon}

\section{(2) OpenEdition}

\section{Journals}

Edición electrónica

URL: http://journals.openedition.org/laboreal/548

DOI: 10.4000/laboreal.548

ISSN: 1646-5237

Editor

Universidade do Porto

\section{Referencia electrónica}

Gilbert Simondon, «El modo de existencia de los objetos técnicos: introducción », Laboreal [En línea], Volume $14 \mathrm{~N}^{0} 1$ | 2018, Publicado el 01 julio 2018, consultado el 23 septiembre 2020. URL : http:// journals.openedition.org/laboreal/548; DOI : https://doi.org/10.4000/laboreal.548

Este documento fue generado automáticamente el 23 septiembre 2020.

\section{(c) (1) \&}

Laboreal está licenciado com uma Licença Creative Commons - Atribuição-NãoComercial 4.0 Internacional. 


\section{El modo de existencia de los objetos técnicos: introducción}

Texto original: Simondon, G. (1969). Introduction. In G. Simondon. Du mode d'existence des objets techniques (pp. 9-16). Paris: Aubier.

Do modo de existência dos objetos técnicos: introdução

Du mode d'existence des objets techniques: introduction

On the mode of existence of technical objects: introduction

\section{Gilbert Simondon}

\section{REFERENCIA}

Artigo original: Simondon, G. (1969). Introduction. In G. Simondon. Du mode d'existence des objets techniques (pp. 9-16). Paris: Aubier.

Agradecemos a la editorial Prometeo por habernos autorizado la publicación de su introducción en idioma español del libro 'el modo de existencia de los objetos técnicos' de Gilbert Simondon.

1 Este estudio está animado por la intención de suscitar una toma de conciencia del sentido de los objetos técnicos. La cultura se ha constituido en sistema de defensa contra las técnicas; ahora bien, esta defensa se presenta como una defensa del hombre, suponiendo que los objetos técnicos no contienen realidad humana. Querríamos mostrar que la cultura ignora en la realidad técnica una realidad humana y que, para cumplir su rol completo, la cultura debe incorporar los seres técnicos bajo la forma de conocimiento y de sentido de los valores. La toma de conciencia de los modos de existencia de los objetos técnicos debe ser efectuada por el pensamiento filosófico, que se encuentra en la posición de tener que cumplir en esta obra un deber análogo al que cumplió en la abolición de la esclavitud y la afirmación del valor de la persona humana.

2 La oposición que se ha erigido entre la cultura y la técnica, entre el hombre y la máquina, es falsa y sin fundamentos; sólo recubre ignorancia o resentimiento. Enmascara detrás de un humanismo fácil una realidad rica en esfuerzos humanos y en 
fuerzas naturales, y que constituye el mundo de los objetos técnicos, mediadores entre la naturaleza y el hombre.

3 La cultura se comporta con el objeto técnico como el hombre con el extranjero cuando se deja llevar por la xenofobia primitiva. EI misoneísmo orientado contra las máquinas no es tanto odio a lo nuevo como negación de la realidad ajena. Ahora bien, este extranjero todavía es humano, y la cultura completa es lo que permite descubrir al extranjero como humano. Del mismo modo, la máquina es el extranjero; es el extranjero en el cual está encerrado lo humano, desconocido, materializado, vuelto servil, pero mientras sigue siendo, sin embargo, lo humano. La mayor causa de alienación en el mundo contemporáneo reside en este desconocimiento de la máquina, que no es una alienación causada por la máquina, sino por el no-conocimiento de su naturaleza y de su esencia, por su ausencia del mundo de las significaciones, y por su omisión en la tabla de valores y de conceptos que forman parte de la cultura. La cultura está desequilibrada porque reconoce ciertos objetos, como el objeto estético, y le acuerda derecho de ciudadanía en el mundo de las significaciones, mientras que rechaza otros objetos, y en particular los objetos técnicos, en el mundo sin estructura de lo que no posee significaciones, sino solamente un uso, una función útil. Frente a este rechazo defensivo, pronunciado por una cultura parcial, los hombres que conocen los objetos técnicos y sienten su significación buscan justificar su juicio otorgando al objeto técnico el único estatuto valorado actualmente por fuera del objeto estético, el de objeto sagrado. Entonces nace un tecnicismo intemperante que no es más que una idolatría de la máquina, y a través de esta idolatría, por medio de una identificación, una aspiración tecnocrática al poder incondicional. El deseo de potencia consagra a la máquina como medio de supremacía, y hace de ella el filtro moderno. EI hombre que quiere dominar a sus semejantes suscita la máquina androide. Abdica entonces frente a ella y le delega su humanidad. Busca construir la máquina de pensar, soñando con poder construir la máquina de querer, la máquina de vivir, para quedarse detrás de ella sin angustia, libre de todo peligro, exento de todo sentimiento de debilidad, y triunfante de modo mediato por lo que ha inventado. Ahora bien, en este caso, la máquina convertida por la imaginación en ese doble deI hombre que es el robot, desprovisto de interioridad, representa de modo demasiado evidente e inevitable un ser puramente mítico e imaginario. Querríamos mostrar precisamente que el robot no existe, que no es una máquina, como no es un ser vivo una estatua, sino solamente un producto de la imaginación y de la fabricación ficticia, deI arte de la ilusión. Sin embargo, la noción de máquina que existe en la cultura actual incorpora en una medida lo suficientemente amplia esta representación mítica deI robot. Un hombre cultivado no se permitiría hablar de objetos o de personajes pintados sobre una tela como de verdaderas realidades que tienen una interioridad, una voluntad buena o mala. Este mismo hombre habla sin embargo de máquinas que amenazan al hombre como si atribuyera a esos objetos un alma y una existencia separada, autónoma, que le confiere el uso de sentimientos e intenciones contra el hombre. La cultura conlleva de este modo dos actitudes contradictorias con respecto a los objetos técnicos: por una parte, los trata como puros ensamblajes de materia, desprovistos de verdadera significación, y que presentan solamente una utilidad. Por otra parte, supone que esos objetos son también robots y que están animados por intenciones hostiles para con eI hombre, o que representan para él un peligro permanente de agresión, de insurrección. AI juzgar bueno conservar el primer carácter, quiere impedir la manifestación deI segundo y habla de poner a las máquinas aI servicio deI hombre, creyendo encontrar de este 
modo, en la reducción a la esclavitud, un medio seguro de impedir toda rebelión. De hecho, esta contradicción inherente a la cultura proviene de la ambigüedad de las ideas relativas aI automatismo, en las cuales se esconde una verdadera falta lógica. Los idólatras de la máquina presentan en general eI grado de perfección de una máquina como proporcional al grado de automatismo. Superando lo que muestra la experiencia, suponen que, a través de un crecimiento y un perfeccionamiento del automatismo, se negará a reunir y a interconectar todas las máquinas entre ellas de manera de constituir una máquina de todas las máquinas.

4 Ahora bien, de hecho, el automatismo es un grado bastante bajo de perfección técnica. Para convertir a una máquina en automática, es preciso sacrificar muchas posibilidades de funcionamiento y muchos usos posibles. EI automatismo, y su utilización baja la forma de organización industrial denominada automación, posee una significación económica o social, más que una significación técnica. EI verdadero perfeccionamiento de las máquinas, aquel deI cual se puede decir que eleva el grado de tecnicidad, corresponde no a un acrecentamiento deI automatismo, sino, por el contrario, al hecho de que el funcionamiento de una máquina preserve un cierto margen de indeterminación. Es este margen lo que permite a la máquina ser sensible a una información exterior. A través de esta sensibilidad de las máquinas a la información se puede consumar un conjunto técnico, y no por un aumento deI automatismo. Una máquina puramente automática, completamente cerrada sobre ella misma en un funcionamiento predeterminado, solamente podría ofrecer resultados sumarios. La máquina que está dotada de una alta tecnicidad es una máquina abierta, y el conjunto de máquinas abiertas supone aI hombre como organizador permanente, como intérprete viviente de máquinas, unas en relación con otras. Lejos de ser el vigilante de una tropa de esclavos, el hombre es el organizador permanente de una sociedad de objetos técnicos que tienen necesidad de él como los músicos tienen necesidad deI director de orquesta. EI director de orquestra solamente puede dirigir a los músicos por el hecho de que toca como ellos, tan intensamente como todos ellos, el fragmento ejecutado; los modera o los apura, pero se ve igual de moderado o apurado que ellos; de hecho, a través de él, el grupo de músicos modera y apura a cada integrante, y el director es para cada uno de ellos la forma en movimiento y actual del grupo mientras existe: es el intérprete mutuo de todos en relación con todos. Del mismo modo, el hombre tiene como función ser el coordinador e inventor permanente de las máquinas que están alrededor de él. Está entre las máquinas que operan con él.

5 La presencia deI hombre en las máquinas es una invención perpetuada. Lo que reside en las máquinas es la realidad humana, el gesto humano fijado y cristalizado en estructuras que funcionan. Estas estructuras tienen necesidad de ser sostenidas en eI transcurso de su funcionamiento, y la mayor perfección coincide con la mayor apertura, con la mayor libertad del funcionamiento. Las calculadoras modernas no son puros autómatas; son seres técnicos que, por sobre sus automatismos de adición (o de decisión por funcionamiento de basculadores elementales), poseen vastísimas posibilidades de conmutación de circuitos, que permiten codificar el funcionamiento de la máquina restringiendo su margen de indeterminación. Gracias a este margen primitivo de indeterminación, la máquina misma puede extraer raíces cúbicas o traducir un texto simple, compuesto de un pequeño número de palabras y de giros, de una lengua a otra. 
6 Todavía más, a través de este margen de indeterminación, y no por los automatismos, las máquinas pueden ser agrupadas en conjuntos coherentes, intercambiar información unas con otras por medio de un coordinador, que es el intérprete humano. Incluso cuando el intercambio de información es directo entre dos máquinas (como entre un oscilador piloto y otro oscilador sincronizados mediante impulsos), el hombre interviene como ser que regula el margen de indeterminación a fin de que se adapte aI mejor intercambio posible de información. Ahora bien, nos podemos preguntar qué hombre puede realizar en él la toma de conciencia de la realidad técnica, e introducirla en la cultura. Esta toma de conciencia puede difícilmente ser realizada por aquel que está ligado a una máquina única por el trabajo y la fijeza de los gestos cotidianos; la relación de uso no es favorable a la toma de conciencia, porque su recomienzo habitual difumina en la estereotipia de los gestos adaptados la conciencia de las estructuras y de los funcionamientos. El hecho de gobernar una empresa utilizando máquinas, o la relación de propiedad, tampoco es más útil que el trabajo para esta toma de conciencia: crea puntos de vista abstractos sobre la máquina, que se juzga a través de su precio y los resultados de su funcionamiento más que por sí misma. El conocimiento científico, que ve en el objeto técnico la aplicación práctica de una ley teórica, no está tampoco aI nivel del dominio técnico.

7 Esta toma de conciencia parecería más bien poder ser una tarea para el ingeniero en organización, que sería como el sociólogo y el psicólogo de las máquinas, porque vive en eI medio de esa sociedad de seres técnicos de los que es la conciencia responsable e inventiva.

8 Una verdadera toma de conciencia de las realidades técnicas aprehendidas en su significación corresponde a una pluralidad abierta de técnicas. Por otra parte, no puede ser de otra manera, porque un conjunto técnico incluso poco extendido comprende máquinas cuyos principios de funcionamiento dependen de dominios científicos muy diferentes. La especialización denominada técnica corresponde con frecuencia a preocupaciones exteriores a los objetos técnicos propiamente dichos (relaciones con el público, forma particular de comercio) y no a una especie de esquema de funcionamiento comprendido en los objetos técnicos. La especialización según las direcciones exteriores a las técnicas crea la estrechez de miras que el hombre cultivado reprocha a los técnicos porque cree distinguirse de ellas: se trata de una estrechez de intenciones, de fines, más que de una estrechez de información o de intuición acerca de las técnicas. Son muy raras en nuestros días las máquinas que no son en alguna medida mecánicas, térmicas y eléctricas a la vez.

9 Para volver a dar a la cultura el carácter verdaderamente general que ha perdido, es preciso poder volver a introducir en ella la conciencia de la naturaleza de las máquinas, de sus relaciones mutuas, y de sus relaciones con el hombre, y de los valores implicados en estas relaciones. Esta toma de conciencia precisa de la existencia, junto con el psicólogo y el sociólogo, del tecnólogo o mecanólogo. Lo que es más, los esquemas fundamentales de causalidad y de regulación que constituyen una axiomática de la tecnología deben ser enseñados de manera universal, como son enseñados los fundamentos de la cultura literaria. La iniciación a las técnicas se debe situar en el mismo plano que la educación científica; es tan desinteresada como la práctica de las artes, y domina tanto las aplicaciones prácticas como la física teórica; puede alcanzar el mismo grado de abstracción y de simbolización. Un niño debería saber qué es una autorregulación o una reacción positiva, al igual que conoce los teoremas matemáticos. 
Esta reforma de la cultura, que procede por ampliación y no por destrucción, podría volver a dar a la cultura actual el verdadero poder regulador que ha perdido. Base de significaciones, de medios de expresión, de justificaciones y de formas, una cultura establece entre aquellos que la poseen una comunicación reguladora; al salir de la vida deI grupo, anima los gestos de aquellos que aseguran las funciones de comando, proveyéndoles las formas y los esquemas. Ahora bien, antes deI gran desarrollo de las técnicas, la cultura incorporaba a título de esquemas, símbolos, cualidades, analogías, los principales tipos de técnicas, dando lugar a una experiencia vivida. Por eI contrario, la cultura actual es la cultura antigua, que incorpora como esquemas dinámicos el estado de las técnicas artesanales y agrícolas de los siglos pasados. Y estos esquemas sirven de mediadores entre los grupos y sus jefes, imponiendo, a causa de su inadecuación a las técnicas, una distorsión fundamental. EI poder se convierte en literatura, arte de opinión, alega sobre verosímiles, retórica. Las funciones directivas son falsas porque ya no existe entre la realidad gobernada y los seres que gobiernan un código adecuado de relaciones; la realidad gobernada implica a hombres y máquinas; el código reposa sólo sobre la experiencia del hombre trabajando con herramientas, experiencia debilitada y lejana porque aquellos que emplean dicho código no levantan, como Cincinato, las manos deI arado [1]. EI símbolo se debilita en simple giro deI lenguaje, lo real está ausente. Una relación reguladora de causalidad circular no se puede establecer entre el conjunto de la realidad gobernada y la función de autoridad: la información no llega a su término porque el código se ha convertido en inadecuado para eI tipo de información que debería transmitir. Una información que expresara la existencia simultánea y correlativa de los hombres y las máquinas debe llevar consigo los esquemas de funcionamiento de las máquinas y los valores que éstos implican. Es preciso que la cultura se convierta en general, ya que hoy se ha especializado y empobrecido. Esta extensión de la cultura, al suprimir una de las principales fuentes de alienación, al reestablecer la información reguladora, posee un valor político y social: puede dar al hombre medios para pensar su existencia y su situación en función de la realidad que lo rodea. Esta obra de ampliación y de profundización de la cultura tiene que cumplir también un rol específicamente filosófico, porque conduce a la crítica de un cierto número de mitos y de estereotipas, como el deI robot, o el de los autómatas perfectos al servicio de una humanidad perezosa y colmada.

Para operar esta toma de conciencia es preciso buscar definir el objeto técnico en sí mismo, a través del proceso de concretización y de sobredeterminación funcional que le da su consistencia al término de una evolución, probando que no podría ser considerado como un puro utensilio. Las modalidades de esta génesis permiten apresar los tres niveles deI objeto técnico y su coordinación temporal no dialéctica: el elemento, el individuo, el conjunto.

11 AI estar el objeto técnico definido por su génesis, es posible estudiar las relaciones entre él y las otras realidades, en particular el hombre en estado adulto y el niño.

Finalmente, considerado como objeto de un juicio de valores, el objeto técnico puede suscitar actitudes muy diferentes según sea tomado en el nivel deI elemento, en el nivel deI individuo o en el nivel deI conjunto. En el nivel deI elemento, su perfeccionamiento no introduce ningún trastocamiento que engendre angustia por estar en conflicto con los hábitos adquiridos: es el clímax del optimismo deI sigla XVIII, que introducía la idea de un progreso continuo e indefinido, aportando una mejora constante de la suerte deI hombre. Por eI contrario, el individuo técnico se convierte durante un tiempo en el 
adversario dli hombre, en su competidor, porque el hombre centralizaba en él la individualidad técnica en un tiempo en donde solamente existían las herramientas; la máquina toma el lugar del hombre porque el hombre cumplía una función de máquina, de portador de herramientas. A esta fase corresponde una noción dramática y apasionada del progreso, que se convierte en violación de la naturaleza, conquista deI mundo, captura de energías. Esta voluntad de poder se expresa a través de la desmesura tecnicista y tecnocrática de la era de la termodinámica, que tiene un giro a la vez profético y cataclísmico. Finalmente, en el nivel de los conjuntos técnicos del siglo XX, el energetismo termodinámico se ve reemplazado por la teoría de la información, cuyo contenido normativo es eminentemente regulador y estabilizador: el desarrollo de las técnicas aparece como una garantía de estabilidad. La máquina, como elemento deI conjunto técnico, se convierte en aquello que aumenta la cantidad de información, lo que acrecienta la neguentropía [2] , que es lo que se opone a la degradación de la energía: la máquina, obra de organización, de información es, como la vida y con la vida, lo que se opone al desorden, aI nivelamiento de toda cosa que tienda a privar al universo de poderes de cambio. La máquina es aquello por medio de lo cual el hombre se opone a la muerte deI universo: hace más lenta, como la vida, la degradación de la energía, y se convierte en estabilizadora del mundo.

Esta modificación de la mirada filosófica sobre el objeto técnico anuncia la posibilidad de una introducción deI ser técnico en la cultura: esta integración, que no se pudo operar de manera definitiva ni en el nivel de los elementos ni en el nivel de los individuos, se podrá operar, con más chances de estabilidad, en el nivel de los conjuntos: la realidad técnica, convertida en reguladora, se podrá integrar a la cultura, reguladora por esencia. Esta integración sólo podía producirse por agregación deI tiempo en el que la tecnicidad residía en los elementos, por fractura y revolución del tiempo en el que la tecnicidad residía en los nuevos individuos técnicos: hoy, la tecnicidad tiende a residir en los conjuntos: puede entonces convertirse en un fundamento de la cultura, a la cual aportará un poder de unidad y estabilidad, volviéndola adecuada a la realidad que expresa y que regula.

\section{NOTAS}

1. Lucia Quincio Cincinato ( $519 \mathrm{aC}-439 \mathrm{aC}$ ) fue cónsul y general de Roma. Se lo suele citar como un ejemplo de integridad y honradez. Según la anécdota a la que se refiere el autor, Cincinato ya se había retirado de la política cuando lo llamaron para que volviera a hacerse cargo de la ciudad frente a la invasión de los aqueos, con el título de dictador. Cuando liegaron hasta él, tenía las manos sobre el arado. Y una vez que consiguió la victoria rechazó el ofrecimiento del Senado para que continuara como dictador y volvió su campo a trabajar la tierra (N. de los T.).

2. En la terminología cibernética, la neguentropía designa la propiedad de las máquinas procesadoras de información de detener la entropía, comprendida desde la termodinámica clásica como la tendencia del universo hacia su equilibrio térmico final, que coincide con la muerte de los seres vivos (N. de los T.). 